\title{
The primary nursing care delivery system within a haemodialysis context - experiences of haemodialysis primary nurses in Sweden
}

\author{
Pia Johansson ${ }^{* 1}$, Kerstin Lundström ${ }^{2}$, Susanne Heiwe ${ }^{3}$ \\ ${ }^{1}$ Department of Nephrology, Karolinska University Hospital, Stockholm, Sweden \\ ${ }^{2}$ Department of Nephrology, Danderyd University Hospital, Stockholm, Sweden \\ ${ }^{3}$ Karolinska Institute, Department of Clinical Sciences, Stockholm, Sweden
}

Received: September 21, 2014

Accepted: May 10, 2015

Online Published: June 10, 2015

DOI: $10.5430 /$ cns.v3n4p7

URL: http://dx.doi.org/10.5430/cns.v3n4p7

\begin{abstract}
Background: Primary nursing is a widespread organisational system for nursing that aims to reduce fragmentation of patient care. The system is implemented in haemodialysis care, but the system was not originally designed for this type of clinical practice. This study explored the model's adaptation to a haemodialysis setting as well as its emotional impact on the primary nurses.

Methods: Nurses were recruited through criteria-based sampling until saturation. Data were collected through semi-structured interviews, and a contextual analysis within a phenomenographic approach was used to process the data.

Results: Primary nurses' pedagogical role needs to be clarified, and the nurses have to be aware that they should provide education to the patients. The outcome space contained experiences of flexible, unclear duties, a sense of sole and overriding responsibility for all aspects of the patient's well-being and management, and unclear professional boundaries. The role was experienced as emotionally demanding.

Conclusions: The primary nursing system needs to be adapted to haemodialysis nursing. Regular counselling should be used as an intervention to improve the primary nurses' emotional situation.
\end{abstract}

Key Words: Adaptation, Education, Chronic kidney disease, Psychological primary nursing care, Qualitative research

\section{BACKGROUND}

Nursing knowledge is the basis for nursing theory, it is the foundation for nursing practice and knowledge development, and it provides direction for the future of nursing. ${ }^{[1]}$ There are various nursing models that consist of and form nursing theories and concepts. ${ }^{[1,2]}$ The Primary Nursing Care Delivery System was developed to reduce fragmentation of patient care, enhance the professional status of nursing, and create professional boundaries. ${ }^{[3,4]}$ The emphasis of primary nursing is on continuity of care for the patient and higher autonomy as well as accountability of practice for the primary nurse (PN). ${ }^{[5]}$ According to Flowers, this care delivery system promotes the maintenance of standards and supports junior health care providers in developing their managerial skills. ${ }^{[6]}$ Primary nursing is today an internationally used care delivery system that consists of eight responsibility components $^{[4,7,8]}$ (see Figure 1).

In Sweden, haemodialysis nurses use the Primary Nursing Care Delivery System because it is thought to be suitable for chronically ill patients. Jovie et al. describe the way

\footnotetext{
*Correspondence: Pia Johansson; Email: pia.johansson@karolinska.se; Address: Departement of Nephrology, Karolinska University Hospital, 171 76 Stockholm, Sweden.
} 
primary nursing was introduced into haemodialysis care. ${ }^{[9]}$ Haemodialysis care is a very complex medical and technical treatment where patient status can be altered very quickly and the nurse has to be able to make quick decisions (e.g. quickly identifying and acting if a patient becomes hypotensive). These nurses have a close relationship with severely ill patients, and they have to reduce the patient's psychological stress in order to improve patient satisfaction. ${ }^{[10,11]}$ The PNs and patients develop a unique relationship because they meet for 3-5 hours treatment sessions 3-5 days per week for the life of the patient. This makes haemodialysis primary nursing different from the initial target group of primary nursing, which was nurses providing care 24 hours per day, seven days a week.

\begin{tabular}{|c|c|c|}
\hline $\begin{array}{l}\text { Professional Nursing Responsibility } \\
\text { Duties } \\
\text { Individual responsibility for decision making } \\
\text { Responsibility to decide what information is } \\
\text { essential for others within the system to have \& } \\
\text { what is not } \\
\text { Both planner \& giver of care }\end{array}$ & $\begin{array}{l}\text { Patient Education } \\
\text { Duties } \\
\text { Fill out a Primary Nurse Monthly Summary form to } \\
\text { be used as: } \\
\text {-an educational tool } \\
\text {-a patient assessment guide } \\
\text {-an evaluation of patient interventions }\end{array}$ & $\begin{array}{r}\begin{array}{r}\text { Patient centred rather than } \\
\text { task centred patient assignment }\end{array} \\
\text { Duties } \\
\text { Match patient needs and nurses' ability } \\
\text { Individual care plan that identifies patient needs }\end{array}$ \\
\hline $\begin{array}{l}\text { Direct Channels of Communication } \\
\text { Duties } \\
\text { Make sure that the communication pyramid is fla } \\
\text { so that important information is not filtered throu } \\
\text { Collect pertinent information for the patient and } \\
\text { through communication with the patient and rela } \\
\text { Initiate communication directly with other memb } \\
\text { Communicate important information needed } \\
\text { members of the health team }\end{array}$ & $\begin{array}{l}\begin{array}{r}\text { hours a d } \\
\text { days a }\end{array} \\
\text { middle person } \\
\text { of hers needs } \\
\text { primary nurse or other }\end{array}$ & $\begin{array}{r}\text { Integrated Thinking \& Operational Responsibility } \\
\text { for the Quality of Patient Care in Primary Nursing } \\
\text { Duties } \\
\text { Assess patient's needs } \\
\text { Be a care planner, but also have operational } \\
\text { responsibility to implement the care plan }\end{array}$ \\
\hline
\end{tabular}

Figure 1. Primary nursing care delivery system

The patients are dependent on haemodialysis treatment, which requires substantial changes in their lifestyle, including dietary and fluid restrictions, complex medication regimes, and frequent haemodialysis sessions. This has been shown to be experienced as burdensome to the patients ${ }^{[12]}$ and to be related to increasingly aggressive patient behaviour towards the staff at the haemodialysis units. ${ }^{[13]}$

Primary nursing within haemodialysis care has been described as having both positive and negative effects. ${ }^{[11,14]}$ This study explored the model's adaptation to a haemodialysis setting as well as its emotional impact on the PNs. It is important to explore this because it might have consequences for quality of nursing care, patient satisfaction, and haemodialysis PNs' health and well-being.

\section{MethodS}

A qualitative research design was chosen because this can be used to obtain a more in-depth understanding of a phenomenon. ${ }^{[15,16]}$ Phenomenography is the empirical study of the qualitatively different ways in which various phenomena are experienced. ${ }^{[17]}$

The participants were recruited by the head nurses at four independent hospital haemodialysis units in February 2008, and none of these nurses had trained patients for home haemodialysis. In order to capture as many different aspects of the phenomenon as possible, purposeful sampling was used. Participants were selected according to a list of factors that were hypothesised to affect experiences of the phenomenon. The hypothesised factors were as follows:

(1) Men-women

(2) 25-60 years of age

(3) Graduated nurse for 1-21 years

(4) 1-6 years as a haemodialysis PN

(5) Part time nurse - full time nurse

Informed consent was obtained from all participants and the research was carried out in accordance with "The Code of Ethics of the World Medical Association" (Declaration of Helsinki).

Data were collected in March 2008 by two haemodialysis nurses with no prior relationship with the participants. All recruited participants agreed to participate in an individual, semi-structured, tape-recordered interview that was transcribed verbatim. The interview schedule was developed on the basis of expertise groups and two pilot interviews. The first question in the interview was: "What duties do you consider as being part of the role as a PN within a haemodialysis unit, and how are you emotionally affected by your role as PN?" The informants were encouraged to freely develop 
their thoughts, and subsequent questions were adjusted to each PN's response. To make sure that the study results represented the participants' ideas rather than the researcher's own frames of reference, four probing strategies were used by the interviewers: repeating, requests for clarification, requests for elaboration, and requests for confirmation. Data were collected until saturation, meaning that no new information was obtained, in seven interviews. The interviews took place at the haemodialysis units and lasted 31-57 minutes.

A contextual analysis was performed manually on the collected data in accordance with a phenomenographic approach $^{[18]}$ and consisted of the following steps:

(1) A preliminary and intuitive interpretation of the interview was conducted in conjunction with each interview.

(2) The interviews were transcribed and read repeatedly by the researchers in order to become familiar with the content and to gain an overall impression of the material.

(3) Irrelevant statements were discarded. Differences and similarities in the participants' experiences were systematically identified by contrasting excerpts from all interviews with one another. A preliminary pattern of descriptive categories was constructed.

(4) The preliminary pattern of categories was scrutinized and revised to construct a set of unique categories. The final descriptive categories were described in the outcome space.

(5) The internal relationships between the categories were described. The aim was to study how the different categories interacted with one another.

The analysis was conducted by the two haemodialysis nurses who conducted the interviews. The analysis was also performed by their supervisor who independently analysed the same data. The results were then compared and no differences were found.

Malterud's guideline for qualitative research was used. ${ }^{[19]}$ To ensure that others could share the data process, the process of data collection and analysis was described thoroughly.

\section{RESUltS}

Four descriptive categories and their internal relationships were identified (see Figure 2). All units used the system, but not in its entirety. For instance, the responsibility to educate the patients was only expressed in one of the interviews. The incomplete implementation of the system caused experiences of not knowing what the role of the PN included, and thus the interpretation of this role could vary among individuals. Also, some PNs expressed feelings of frustration and stress related to their role. Haemodialysis care is a special context because the PN and his or her patient develop a life-long relationship where they meet three to five times a week, and our findings showed that some PNs experienced this relationship with their patients as energizing, while others found it to be emotionally exhausting. The descriptive categories and the internal relationships are described in detail below.

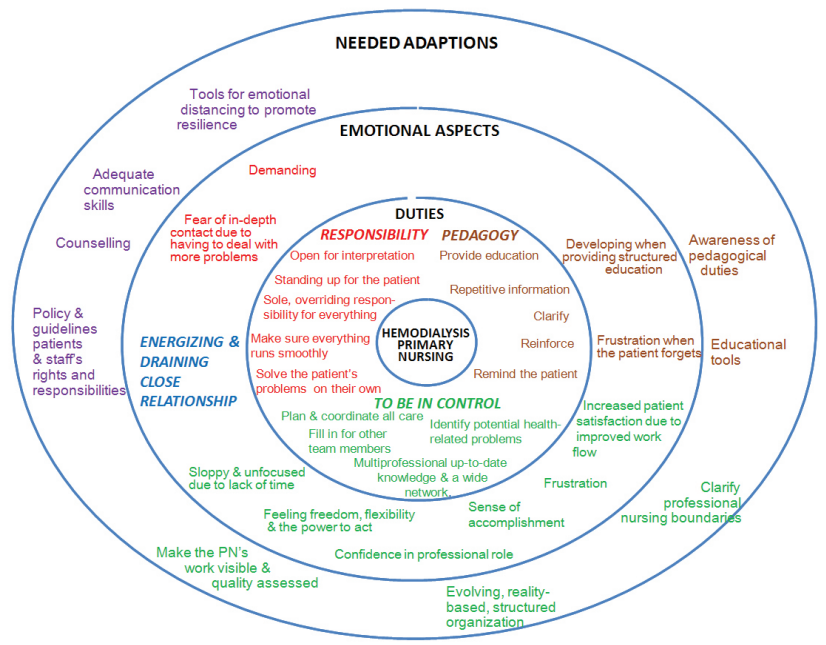

Figure 2. Four descriptive categories and their internal relationships are presented in different colours

\subsection{Responsibility for all aspects of the patient's well- being and management}

This descriptive category describes the participants' sense of standing up for the patient as well as having sole and overriding responsibility for all aspects of the patient's care. This feeling was experienced despite the responsibilities of the other health team members. There were various reasons for this, but the primary reason was the desire to make sure that everything worked smoothly for the patient, their relatives, and the other health-care professionals. The participants also described how they took it upon themselves to reinforce information provided by other health-care professionals, but their reasons for doing this were not clear. Some of the participants also described how they initially tried to solve the patient's problem by themselves instead referring the patient to, for example, a social worker. This feeling of overriding responsibility was emotionally demanding on the participants. Our data also showed that some PNs developed a fear that the long-term contact with the patient would increase the risk of identifying even more problems that had to be dealt with and that this would be too much. Keeping a low profile was therefore used as strategy to avoid becoming emotionally overwhelmed.

The informants described how the role of a haemodialysis $\mathrm{PN}$ was open for interpretation because the work description 
was unclear and only contained a few work directions. It was therefore possible for the primary nurse her or himself to set the level of professional ambition. This had both positive and negative consequences. One informant expressed how the unclear role made it possible for him not to get too involved and how this made the job less emotionally demanding. Another informant described how one could alter their work schedule to be out of sync with the patient's dialysis schedule such that one would only have to meet with a particular patient three times per year.

“... there are different ways of organising primary nursing ... We have different ideas about what's really included ... I want to keep a low profile ... I can't act like their parents ... it gets to be too much."

“... there are different ways of organising primary nursing ... We have different ideas about what's really included"

“The patient's and the doctor's goals aren't always the same. That's how it is. It's me who's the go-between ... sometimes dialysis accesses [AV-fistulae] are created on an ongoing basis whether or not the patient wants it ... I'm standing up for you in your decision, we say no if you don't want it"

“... test her on her homework in Swedish because she's learning Swedish. Such things are important to her.'

\subsection{Pedagogical duties}

In the present study, providing information was defined as a one-way communication where the provider of the information does not follow-up that the receiver has understood the information. Education includes both the providing of information and a follow-up of the receiver's understanding, and the aim of such education is a behavioural change.

The PNs provided a great deal of logistic and health-care information to the patients, their relatives, and other healthcare professionals. When initiating haemodialysis treatment, the information was primarily verbal and unstructured. At a later stage, the information varied significantly between PNs in terms of content and frequency. They continuously provided the patients with information, and they also had to clarify and reinforce information from other health-care professionals.

“... you try to explain things the whole time that you're doing them."
"I reinforce the sort of things that the social worker and dietician have gone through - you sort of feed it in ..."

Only one PN expressed that she educated the patients. A structured education plan was used, including checklists with information about types of training and education that were to be given, as well as the order and time intervals that were to be followed. This ensured that the education was documented and automatically followed up. It also enabled other nurses to continue the educational process and for them to identify and clarify unrecognised needs.

"If the patient puts on a lot of weight it can be really dangerous, so it's very important to educate patients."

\subsection{To be in control}

This category describes the experience of being responsible for having logistical and medical control. The PNs expressed that they felt expected to plan and coordinate all of the activities involving the patient's care, wishes, and practical issues (e.g. reminding the patients of various appointments), as well as to identify any potential health-related problems. To do this, they had to have the most up-to-date information about the patient as well as a wide knowledge of multi-professional healthcare and a wide network. Being in control was related to positive emotions because it gave a sense of accomplishment and confidence in one's professional role and because it improved work-flow and increased patient satisfaction. However, the participants also described how there was a lack of clear boundaries for the PN's role, and they provided potential reasons for this. In one unit, the physicians were only available two to three times a week, and this increased the nurses' expectations to fill in for the physicians. Another underlying reason was that in some units several renal physicians expected to be continuously updated on patient information (i.e. test results, AV-fistulae function, home situation, compliance to medication, nutritional status, degree of mobilisation, etc.) from the PN, and the nurses felt responsible to provide such updates even though it was expressed as taking time away from nursing care. This was related to experiences of feeling sloppy and unfocused in performing one's duties. Because most of the nursing interventions could not be quantitatively assessed, evaluated, and documented, the participants expressed how their in-depth knowledge was not made visible. This caused feelings of frustration and of being invisible to everyone (including the PNs themselves) except the patient. However, when getting positive feedback from the patient the PN felt visible, and this created a sense of personal accomplishment. This sense was even stronger 
when a patient expressed a wish to be taken care of by the PN.

“... planning before procedures, examinations, possible operations. When I say planning I mean some blood-work, preparation, even sorting out the paperwork to see that everything is organised in advance /.../ everything really involves a lot of planning... whether it's patients wanting to lie in bed or sit in a chair or us knowing that a certain catheter perhaps doesn't work on a particular machine.'

"[Contact]... with home, school, social services, dialysis, with the children's ward, with the Gothenburg transplant unit, with different authorities, with the social worker, with the physiotherapist, with the dietician and the kitchen staff ... relatives, schools, and the whole lot."

“... it is easier to follow-up. If you only have a few patients it's easier to be in control as you look at fistulae blood-flow and recirculation in order to prevent fistulae dysfunction."

“... I don't think it's reasonable. . . that I should have to be up-to-date with tests and lab results all the time ... when it's just as easy for the physician to press a key and get the information [on the computer].... I haven't only got my own patients ... I've also got responsibility for all the others when I'm on the floor ... I have to know that, 'Oh my God, this one's blood pressure is falling', and 'Oh dear, this one's experiencing severe pain'..."

"My work isn't down on paper. I can't produce statistics and show around Sweden [at meetings] and the whole of Europe and out in the world/... / you don't have a graph that shows this is how our patients are feeling due to our staffs' [nurses'] ability to make them feel comfortable and well."

\subsection{Draining and energizing close relationship}

This category describes how the close relationship between the PN and haemodialysis patients affected the PNs emotionally. The frequent treatment of the same patients on a life-long basis caused feelings of "being drained of all your energy." Participants described how some patients constantly complained or demanded attention and never showed any appreciation no matter what the PN did. This created feelings of emotional exhaustion. To cope with this situation the PNs described how they helped each other by shifting patients between each other and by discussing thoughts and emotions that a patient might have evoked. The participants described how the close relationship with the patient was related to having to deal with difficult emotions. Negative psychological stress was experienced when there was a risk that communication with the patient or relatives would entail emotions that would be difficult to handle, or when they felt that their role as a PN also included dealing with emotions directed toward the PN her or himself and their colleagues. However, positive psychological effects were also experienced and described. For instance, the PN's role was described as stimulating and rewarding when there was good personal chemistry between nurse and the patient. Also, when getting positive feedback from relatives after having listened to relatives' questions and anxieties, even if for only a short of time, the PNs experienced a sense of personal accomplishment.

"Because our patients come three times a week there's quite a lot of contact. Actually, there can be a bit too much ..."

“... I have a lady who's so ... she just drains you. And it's never right and there's always a load of problems ... Well, I just can't cope with it ..."

"I had to deal with relatives' anger and sorrow, which they came right out with, and of course I had to help my colleagues who had to listen to it all from the patients and relatives. I had to stand in the middle and try to absorb all this, then re-direct it ..."

“... it's nice to know that you have a patient, that you can follow things up and that you learn a lot yourself ... You get to know the whole family, including the dog." [laughter]

"... or she [the patient] could almost be my best friend even though we don't speak the same language ... It is almost too perfect sometimes."

\section{Discussion}

According to Jost et al. "nursing care delivery models need to be evolving and reality-based, as they serve to organize the allocation of nursing resources. How nursing resources are allocated is associated with patient and professional RN satisfaction. Care delivery models must be evolving within 
today's dynamic healthcare environment and must be structured within the context of a professional practice." ${ }^{[20]}$ Our findings regarding the haemodialysis primary nursing model provide important information regarding how the haemodialysis PNs use the primary nursing model to be able to focus on the evolution of people's experienced health problems and their diseases. This empowers the PN's ability to guide the patient toward the overarching goal of health and healing and to reduce the burden of their illness. Furthermore, our findings indicate that by using the model, nurses get to know the patient and his/her needs to a greater extent, which could increase patient safety. Our findings also showed failures in implementing the primary nursing model as a whole, for in stance being able to set your own working schedule in a way that resulted in only meeting your primary nursing patient a few time per year. This is neither in accordance with the model nor with person-focused care, and this shows a need for organizational improvement.

In concordance with Dobson et al. data from the present study indicated that primary nursing care had both positive and negative effects in haemodialysis care. ${ }^{[14]}$ Primary nursing is a powerful facilitator for achieving a delivery system of professional nursing where the patient's needs and the nurse's ability is supposed to be matched. ${ }^{[4,21]}$ The system is supposed to increase patient outcomes with continuity, enhance the professional status of nursing, clearly create professional nursing boundaries, and increase job satisfaction. ${ }^{[3,22]}$ Findings from the present study showed that there were problems associated with the adaptation of this system to haemodialysis care in Sweden.

The nurses' experience of what is included in the role as PN varied and was not as clearly defined as, for instance, by Ilumin, ${ }^{[8]}$ and the PNs experienced a sense of sole and overriding responsibility for all aspects of the patient's well-being and management. Previous research has identified accountability for one's patient, ${ }^{[8]}$ but to our knowledge no study has identified this significant feeling of responsibility for all aspects of the patient's health-care and social well-being. Our findings also showed that the PNs deviated from the system by including medical directions among their duties that were irrelevant for the professional nursing process and were performed at the expense of time dedicated to nursing care. Our data indicate a need to clarify professional nursing and its boundaries. Organization and leadership form the cornerstones for successful implementation. ${ }^{[23]}$ Transformational leadership could help improve the structure of the model by formally incorporating the system's basic functions into each nurse's role description, and this could help create a culture and context that promotes primary nursing. Dobson et al. have shown that primary nursing is the most effective way to provide nursing care within haemodialysis care. ${ }^{[14]}$ They also highlight the need for developing guidelines and continuously developing educational interventions in order to support the PNs' role. ${ }^{[14]}$ By doing so PNs would be able to prioritize their duties and stop feeling guilty about not being able to meet all of their patients' needs because this will never be possible due to lack of adequate health-care resources. ${ }^{[4]}$ Proactive attempts to develop methods that evaluate and document the effects of nursing interventions on patient health outcomes ${ }^{[24]}$ would also make their professional role more visible to themselves and to other health-care professionals. A well-adapted and structured primary nursing system within haemodialysis care could also function as a facilitator for research utilization and evidence-based practice because the PNs' roles include acting as direct channels of communication, collectors and providers of information and education, and sources of deep and wide-ranging knowledge.

Education is one part of the primary nursing system. Education provided by nurses has beneficial effects on patients' health and well-being by increasing self-care, compliance with medical treatment, and improving treatment outcomes. ${ }^{[25]}$ Not providing education within haemodialysis nursing might cause morbidity and perhaps also mortality if the patient never reaches the important goals of lifestyle changes and compliance with medical treatment. However, only one of the PNs interviewed for this study mentioned education as being one of the duties of PNs. The focus was instead on providing the same information over and over again, which caused frustration. The extensive need for repetitive information might be related to the cognitive dysfunction that is present in adults undergoing haemodialysis. ${ }^{[26,27]}$ If the PNs had provided education, they most likely would not have had to repeat the information as often and this might have reduced their feelings of frustration. Our findings indicated that the PNs needed to be aware of their educational responsibility, to document their pedagogical interventions, and to understand the difference between providing information and providing education. Research has shown that nurses often do not reflect on the fact that they are in a teaching situation, and terms such as information, education, guidance, instruction, and support are often used by nurses without them being aware of the meanings of these words. ${ }^{[28,29]}$

In the present study, none of the PNs mentioned recognition or increased utilization of knowledge and skills as things they had experienced in their roles as PNs, which is in contrast to the findings by Roberts and Sellick et al. ${ }^{[3,22]}$ An experience of job satisfaction was, however, present when feeling that one has accomplished something worthwhile, has had the opportunity to voice one's opinions, has been part of the decision-making process, and has been able to set one's own 
work schedule. Because negative psychological stress was the dominant feeling among the PNs, it is important that positive feelings are reinforced and negative factors are reduced by the leadership of the organization.

The PNs in the present study experienced high levels of daily stress. They experienced their role as emotionally demanding due to their close relationships with their patients, the patients' constant demands, unclear role descriptions, and the seemingly unlimited number of duties they are expected to perform. There were also feelings of apprehension of having too close of a relationship to the patient and of having to deal with anger and sorrow from patients and their relatives. This is in agreement with previous research findings. ${ }^{[30]}$ Long-term emotional stress at work can increase the risk of emotional exhaustion. ${ }^{[31,32]}$

Jones et al. showed that haemodialysis staff often experienced an aggressive work environment related to patients' frustration and anger over waiting to be put on or taken off the dialysis machine, having to wait for transportation back and forth from the dialysis centre (sometimes for hours), and how the disease and treatment regime limits their quality of life (e.g. a restricted diet and fluid management, sexual dysfunction, and limited spare time and social life). ${ }^{[33]}$ Similar to our findings, Jones et al. also found that the life-long treatment where nurse and patient meet 3-5 times a week could be energizing because a close relationship could evolve, but it could also have a draining effect, especially if the patient showed no interest in getting along with the staff. ${ }^{[33]}$ The regular and close relationship at the unit makes haemodialysis primary nursing unique compared to the context in which the primary nursing model was originally developed. Several studies have shown an increase in aggressive patient behaviour towards haemodialysis staff. ${ }^{[13,34-36]}$ Ballerini et $a l$. describe how this patient group can be experienced as arrogant, aggressive, undisciplined, angry, annoying, and selfish by nephrologists and renal nurses. ${ }^{[36]}$ Research has shown that policies and guidelines need to be developed to clarify patients' and staffs' rights and responsibility in order to prevent aggressive behaviour. ${ }^{[34,37]}$ Data from the present study show that haemodialysis nurses need to be provided with regular counselling in order to prevent emotional exhaustion. Furthermore, it is possible that the haemodialysis PNs would handle patients and conflicts better if they possessed adequate communication skills and had access to regular psychosocial training. ${ }^{[38]}$ This could be a strategy to create a balance between energizing and draining emotional relationships with the patients and thereby maintain psychological well-being among the PNs. Research has also shown that high levels of emotional exhaustion in nurses and physicians are associated with poor patient satisfaction in haemodialysis units. ${ }^{[31]}$

\section{Conclusion}

Patients with haemodialysis have a chronic and lifethreatening disease associated with multiple comorbidities, and they are dependent on the dialysis machine and the nurses' skills. Chronic kidney disease and its symptoms force the patients to change and adapt their entire life situation. This study identified duties and emotional aspects related to primary nursing within a haemodialysis context. It also highlighted areas where adaptations are necessary to achieve improved patient and staff satisfaction. Being a haemodialysis PN was shown to be a special form of PN. It included responsibilities for highly technical care as well having to deal with patients who are living with a chronic disease and comorbidities, to help patients solve problems, to support the patients in changing their life, and to try to make the patient's life easier. Education was shown to be an important tool in order to make the patient's life easier. Also, the PNs were responsible for quickly identifying health problems and helping the patients to solve such problems. The identified duties were related to various emotional aspects ranging from feelings of energizing to feelings of emotional exhaustion because of the lifelong relationship with the patient. The results indicated that haemodialysis PNs need education in pedagogy, tools for emotional distancing, counselling, and policies and guidelines concerning the patients' and staffs' rights and responsibilities.

The results from the present study indicate that haemodialysis leadership and organisations need to adapt the Primary Nursing Care Delivery System to a hemodialysis context. Strategies need to be developed for including education as part of the haemodialysis PN's role, which might improve patient outcomes. Future research is needed concerning what the PNs' responsibilities should be within haemodialysis care and how their work can be assessed and quality assurance can be guaranteed. Regular counselling should be used to improve the PNs' emotional situation and to reduce feelings of emotional exhaustion.

\section{REFERENCES}

[1] George JB. Nursing Theories: The base for professional nursing practice. 5 ed. Upper Saddle River, N.J: Prentice Hall; 2002. 611 p.

[2] Kristoffersen NJ, Nortvedt F, Skaug EA. Grundläggande omvårdnad
[Basis for nursing care] 4th rev. Stockholm: Liber; 2006. 13-101 p.

[3] Roberts LE. Primary nursing Do patients like it Are nurses satisfied Does it cost more? The Can Nurse. 1980 Dec; 76(11): 20-3. PMID:6904233. 
[4] Manthey M. The Practice of Primary Nursing. London: The King's Fund Centre; 1992. 76 p.

[5] Makinen A, Kivimaki M, Elovainio M, et al. Organization of nursing care and stressful work characteristics. J Adv Nurs. 2003; 43(2): 197-205. http://dx.doi .org/10.1046/j.1365-2648.2003.0 2694. $\mathrm{x}$

[6] Flowers M. Testing ground. Nurs Times. 1992 Aug; 88(34): 34-5. PMID:1513713.

[7] Molzahn AE. Primary nursing and patient compliance in a hemodialysis unit. ANNA J. 1989 Jun; 16(4): 267-72. PMID:2742393.

[8] Ilumin MP. A continuous quality improvement (CQI) initiative: focusing on primary nurse accountability. Nephrol Nurs J. 2003 Feb; 30(1): 33-7. PMID:12674947.

[9] Jovie EM, Calaway L, Jorgensen L, et al. The practical aspects of primary nursing practice. ANNA J. 1988 Jun; 15(3): 157-58, 192-93

[10] Kotzabassaki S, Parissopoulos S. Burnout in renal care professionals. EDTNA ERCA J. 2003 Oct-Dec; 29(4): 209-13. PMID:14748431. ht tp://dx.doi.org/10.1111/j.1755-6686.2003.tb00316.x

[11] Quirk BP. Primary patient care in a chronic outpatient hemodialysis unit. ANNA J. 1998 Jun; 25(3): 301-6, 319. PMID:9801486.

[12] Khalil AA, Frazier SK. Depressive symptoms and dietary nonadherence in patients with endstage renal desease receiving hemodialysis: a review of quatitative evidence. Issues Ment Health Nurs. 2010 May; 31(5): 324-30. PMID:20394478. http://dx.doi.org/10.3109 /01612840903384008

[13] Zampieron A, Saraiva M, Pranovi R, et al. Survey on violence and aggression prevention and management strategies in European renal units. J Ren Care. 2010 Jun; 36(2): 60-7. PMID:20591000. http://dx.doi.org/10.1111/j.1755-6686.2010.00148.x

[14] Dobson S, Tranter S. Organising the work: choosing the most effective way to deliver nursing care in a hospital haemodialysis unit. Ren Soc Australas J. 2008 Jul 1; 4(2): 59-63.

[15] Shortell SM. The emergence of qualitative methods in health services research. Health Serv Res. 1999 Dec; 34(5 Pt 2): 1083-90. PMID:10591274.

[16] Sofaer S. Qualitative research methods. Int J of Qual Health Care. 2002 Aug; 14(4): 329-36. PMID:12201192. http://dx.doi.org /10.1093/intqhc/14.4.329|

[17] Marton F. Phenomenography - describing conceptions of the world around us. Instr Sci. 1981; 10(2): 177-200. http://dx.doi.org/1 $0.1007 / \mathrm{BF} 00132516$

[18] Starrin B, Svensson PG. Kvalitativ metod och vetenskapsteori. [Qualitative research methodology and scientific research] Lund (Sweden): Studentlitteratur; 1994; 125-8 p.

[19] Malterud K. Qualitative research: standards, challenges, and guidelines. Lancet. 2001; 358(9280): 483-88. http://dx.doi.org/10. 1016/S0140-6736(01) 05627-6

[20] Jost SG, Bonnell M, Chacko SJ, et al. Integrated primary nursing: a care delivery model for the 21 st-century knowledge worker. Nurs Adm Q. 2010 Jul-Sept; 34(3): 208-16. PMID:20562570. http://dx.doi.org/10.1097/NAQ.0b013e3181e7032c

[21] Deiman PA, Noble E, Russell ME. Achieving a professional practice model. How primary nursing can help. J Nurs Adm. 1984 Jul-Aug; 14(7-8): 16-21. http://dx.doi.org/10.1097/00005110-198 407000-00005

[22] Sellick KJ, Russell K, Beckmann L. Primary nursing: an evaluation of its effects on patient perception of care and staff satisfac- tion. Int J Nurs Stud. 2003 Jul; 40(5): 545-51; discussion 553-54 http://dx.doi.org/10.1016/S0020-7489(03)00064-6

[23] Rycroft-Malone J. The PARIHS framework-a framework for guiding the implementation of evidence-based practice. J Nurs Care Qual. 2004 Oct-Dec; 19(4): 297-304. PMID:15535533. http: //dx.doi.org/10.1097/00001786-200410000-00002

[24] Saranto K, Kinnunen U. Evaluating nursing documentation - research design and methods: systematic review. J Adv Nurs. 2009 Mar; 65(3): 464-76. PMID:19222644. http://dx.doi.org/10.1111/j.136 5-2648.2008.04914.x

[25] Golper T. Patient education: can it maximize the success of therapy? Nephrol, Dial, Transplant. 2001; 16(7): 20-4. http://dx .doi .org /10.1093/ndt/16.suppl_7.20

[26] Etgen TD, Sander M, Chonchol C, et al. Chronic kidney disease is associated with incident cognitive impairment in the elderly: the INVADE study. Nephrol Dial Transplant. 2009 Oct; 24(10): 3144-150. PMID:19461010. http://dx.doi.org/10.1093/ndt/gfp230

[27] Pereira AA, Weiner DE, Scott T, et al. Cognitive function in dialysis patients. Am J Kidney Dis. 2005; 45(3): 448-62. PMID:15754267. http://dx.doi.org/10.1053/j.ajkd.2004.10.024

[28] Friberg F. Pedagogical Encounters Between Patients and Nurses in a Medical Ward - Towards a Caring Didactics from a Life-World Approach. [dissertation]. Gothenburgh: Acta Universitatis Gothenburgensis; 2001. $258 \mathrm{p}$.

[29] Öhman B. The nurse's patient education within geriatric care and rehabilitation. [dissertation] Gothenburgh: HLS förl; 2003. 183 p.

[30] Dermody K, Bennett PN. Nurse stress in hospital and satellite hemodialysis units. J Ren Care. 2008 Mar; 34(1): 28-32. PMID:18336520. http://dx .doi.org/10.1111/j.1755-6686. $2008.00007 . \mathrm{x}$

[31] Argentero P, Dell'Olivo B, Ferretti MS. Staff burnout and patient satisfaction with the quality of dialysis care. Am J Kidney Dis. 2008 Jan; 51(1): 80-92. PMID:18155536. http://dx.doi.org/10.10 53/j.ajkd.2007.09.011

[32] Klersy C, Callegari A, Martinelli V, et al. Burnout in health care providers of dialysis service in Northern Italy-a multicentre study. Nephrology, Dialysis, Transplantation. 2007 Aug; 22(8): 2283-90. PMID:17442744. http://dx.doi.org/10.1093/ndt/gfm111

[33] Jones J, Nijman H, Ross J, et al. Aggression on haemodialysis units: a mixed method study. J Ren Care. 2014 Sept; 40(3): 180-93. PMID:25042357. http://dx.doi.org/10.1111/jorc. 12068

[34] King K, Moss AH. The frequency and significance of the "difficult" patient: the nephrology communities perceptions. Adv Chronic Kid Dis. 2004 Apr; 11(2): 234-39. PMID:15216497. http://dx.doi . org/10.1053/j . arrt . 2004.02.004

[35] Sedgewick J. Nurses at breaking point: violence and aggression in renal units. Nephrology News. 2005; 6-7.

[36] Ballerini L, Paris V. Nosogogy: when the learner is a patient with chronic renal failure. Kidney Int Suppl. 2006 Nov; 103: 122-6. PMID:17080103.http://dx.doi.org/10.1038/sj.ki.50019 28

[37] Burns T, Smyth A. Reducing aggression in the haemodialysis unit by improving the dialysis experience for patients. Ren Soc Australas J. 2011; 7(2): 79-89.

[38] Dolan G, Strodl SE, Hamernik E. Why renal nurses cope so well with their workplace stressors. J Ren Care. 2012 Dec; 38(4): 222-32. PMID:22934929. http://dx.doi.org/10.1111/j.1755-6686. $2012.00319 . x$ 